\title{
Dietary soy isoflavones alleviate dextran sulfate sodium-induced inflammation and oxidative stress in mice
}

\author{
BIN WANG $^{1}$ and CUNBING WU ${ }^{2}$ \\ ${ }^{1}$ Department of Food and Nutritional Engineering, Jiangsu Food and Pharmaceutical Science College; \\ ${ }^{2}$ Department of Food Engineering, Jiangsu Polytechnic of Finance and Economics, Huaian, Jiangsu 223005, P.R. China
}

Received November 22, 2015; Accepted February 24, 2017

DOI: $10.3892 /$ etm.2017.4469

\begin{abstract}
It has been hypothesized that soy isoflavones exhibit anti-oxidative and anti-inflammatory functions, however, the effects of soy isoflavones on inflammatory bowel diseases remain unknown. Therefore, the present study aimed to investigate the effect and underlying mechanism of dietary soy isoflavones on dextran sulfate sodium (DSS)-induced colitis. Mice were administered DSS and soy isoflavones, and histomorphometry, oxidative stress, inflammation and intestinal tight junctions were determined. The current study demonstrated that dietary soy isoflavones alleviated DSS-induced growth suppression, colonic inflammatory response, oxidative stress and colonic barrier dysfunction. DSS treatment was indicated to activate Toll-like receptor 4 (TRL4) and myeloid differentiation protein 88 (MyD88) in mice, whereas dietary soy isoflavones inhibited Myd88 expression in DSS-challenged mice. In conclusion, dietary soy isoflavones alleviate DSS-induced inflammation in mice, which may be associated with enhancing antioxidant function and inhibiting the TLR4/MyD88 signal.
\end{abstract}

\section{Introduction}

Inflammatory bowel disease (IBD), comprising Crohn's disease and ulcerative colitis, is multifactorial and results from an interaction between genetic, microbial, autoimmune and environmental factors (1). The incidence of IBD is associated with dietary compositions, saturated fats, depression, impaired sleep and serum vitamin D concentrations (2-4). The pathogenesis of IBD is a chronic relapsing inflammatory disorder leading to neutrophil accumulation, gastrointestinal inflammation with villus atrophy and loss of crypts, and is accompanied

Correspondence to: Professor Bin Wang, Department of Food and Nutritional Engineering, Jiangsu Food and Pharmaceutical Science College, 4 Meicheng Road, Higher Education Park in Huaian, Huaian, Jiangsu 223005, P.R. China

E-mail: wang_bin@mails.ucas.ac.cn

Key words: soy isoflavones, inflammation, oxidative stress, dextran sulfate sodium by diarrhea, blood in stool, weight loss, disturbed intestinal barriers and dysfunction of tight junctions $(5,6)$. As inflammation is closely associated with the generation of free radical species, oxidative stress has been proposed as a mechanism underlying the pathophysiology of various inflammation-associated diseases, including IBD $(7,8)$. Experimental and clinical evidence suggests that antioxidant compounds may serve as the potential therapeutic modalities of human IBD (8-11).

Soy isoflavones are diphenolic compounds that are present in plants such as soybeans, red clover and kudzu root. It has been demonstrated that they have antioxidant properties via detoxifying free radical species and upregulating antioxidant genes (12). Soy isoflavones are also associated with cell survival, cell cycle, inflammation and apoptosis, and they suppress nuclear factor (NF)- $\mathrm{B}$ and other signaling pathways (12). However, the effects of soy isoflavones on dextran sulfate sodium (DSS)-induced IBD remain unknown. Thus, the aim of the present study was to investigate the protective effect of soy isoflavones in DSS-challenged mice via assessing morphology and performing reverse transcription-quantitative polymerase chain reaction (RT-qPCR) analyses.

\section{Materials and methods}

Animal model and groups. A total of 40, 5-week old female ICR mice weighing 22.66 $0.12 \mathrm{~g}$ were obtained from Changsha Well-Bio (Changsha, China). Mice were divided into four groups ( $\mathrm{n}=10$ in each): Control (Cont), in which mice were fed a basic diet (13) and tap water; a DSS-treated group (DSS), in which mice had ad libitum access to 5\% DSS solution (Kayon Biotechnology, Co., Ltd., Shanghai, China) supplied as drinking water; a soy isoflavonones supplemented group (SIF), in which $0.5 \%$ soy isoflavones were mixed in the feeding diet (Xi'an Rongsheng Biotechnology, Co., Ltd., Shaanxi, China) according to previous studies (14); and a soy isoflavones and DSS-treated group (SDS), in which mice were treated with DSS and soy isoflavones as previously described. All mice were housed in polycarbonate cages in a room with a controlled temperature of $25 \pm 3^{\circ} \mathrm{C}$, a humidity of $50 \pm 5 \%$ and a 12-h light/dark cycle. Mice were allowed ad libitum access to laboratory strip chows throughout the experimental period.

Following the 7-day experimental period, all mice were sacrificed via general anesthetic with Zoletil $50(10 \mathrm{mg} / \mathrm{kg}$ diluted in saline; Virbac S.A., Carros, France). Subsequently, 
colons were harvested and colon length was measured $(n=10)$. Prior to sacrifice, 10 blood samples from each group were collected via orbital vein bleeding after mice were sedated. In addition, colon tissues from each mouse were harvested and immediately frozen in liquid nitrogen and stored at $-70^{\circ} \mathrm{C}$ for subsequent gene expression analysis $(n=6)$. The present study was conducted according to the guidelines of the Declaration of Helsinki and all procedures involving animal subjects were approved by the Animal Welfare Committee of the Jiangsu Food and Pharmaceutical Science College (Huaian, China).

Histomorphometry determination. The morphological evaluation following treatment with DSS was performed using hematoxylin and eosin (H\&E) staining. Briefly, one section of each colon sample $(0.5 \mathrm{~cm})$ was fixed in $4 \%$ neutral buffered formalin, processed using routine histological methods and mounted in paraffin blocks (room temperature). Each sample was cut into $6 \mu \mathrm{m}$-thick sections and stained with H\&E. All specimens were examined under a light microscope (Nikon Corporation, Toyko, Japan). Villus height and crypt depth were measured using Image-Pro Plus version 6.0 software (Media Cybernetics, Inc., Rockville, MD, USA) (15).

Serum oxidative indexes. Harvested blood samples were stored at $4^{\circ} \mathrm{C}$ for $4 \mathrm{~h}$, when serum samples were separated from blood via centrifugation at $3,500 \mathrm{x} \mathrm{g}$ and $4^{\circ} \mathrm{C}$ for $15 \mathrm{~min}$. Malondialdehyde (MDA) and total antioxidant capability (T-AOC) were measured using assay kits in accordance with the manufacturer's instructions (MDA, A003-1; T-AOC, A0015-1; both Nanjing Jiancheng Bioengineering Institute, Nanjing, China).

cDNA synthesis and quantification of $m R N A$ by $R T-q P C R$. Total RNA was isolated from liquid nitrogen pulverized tissues using TRIzol reagent according to the manufacturer's protocol (Invitrogen; Thermo Fisher Scientific, Inc., Waltham, MA, USA) and then treated with DNase I (Invitrogen; Thermo Fisher Scientific, Inc.) according to the manufacturer's protocol. Synthesis of the first strand (cDNA) was performed with oligo (dT) 20 and Superscript II reverse transcriptase using the following program: $42^{\circ} \mathrm{C}$ for $2 \mathrm{~min} ; 37^{\circ} \mathrm{C}$ for $15 \mathrm{~min}$; followed by $85^{\circ} \mathrm{C}$ for $5 \mathrm{sec}$ (Invitrogen; Thermo Fisher Scientific, Inc.).

Primers were designed with Primer 5.0 according to the gene sequence of mouse (www.ncbi.nlm.nih. gov/nuccore/?term=Mus+musculus) to produce an amplification product. The primer sets used are presented in Table I. The protocol of RT-qPCR was completed using the SYBR ExScript RT-qPCR kit (Takara Biotechnology Co., Ltd.). A total reaction system of $10 \mu \mathrm{l}$ contained $1 \mu \mathrm{l}$ cDNA from the aforementioned PCR, $5 \mu$ l SYBR Premix EX Taq, $0.5 \mu$ l of each

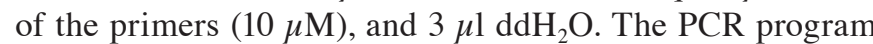
was as follows: Denaturation at $95^{\circ} \mathrm{C}$ for $2 \mathrm{~min}$; followed by 45 cycles at $95^{\circ} \mathrm{C}$ for $10 \mathrm{sec}, 59^{\circ} \mathrm{C}$ for $20 \mathrm{sec}$ and $72^{\circ} \mathrm{C}$ for $30 \mathrm{sec}$ according to previous studies $(16,17)$. Relative gene expression was normalized to $\beta$-actin and expressed as a ratio to the expression in control group using the formula $2^{-(\Delta \Delta \mathrm{Cq})}(18)$, where $\Delta \Delta \mathrm{Cq}=\left(\mathrm{Cq}_{\text {Target }}-\mathrm{Cq}_{\beta \text {-actin }}\right)_{\text {treatment }}-\left(\mathrm{Cq}_{\text {Target }}-\mathrm{Cq}_{\beta \text {-actin }}\right)_{\text {control }}$. Therefore, relative expression of target genes in the control group was: Relative gene expression levels represented the comparison vs. control group; results were reported as a fold-change from the control value.

Statistical analysis. All statistical analyses were performed using SPSS 17.0 software (SPSS, Inc., Chicago, IL, USA). Group comparisons were performed using a one-way analysis of variance to assess the homogeneity of variances via Levene's test and followed with Tukey's multiple comparison test. Data are expressed as the mean \pm standard error of the mean. $\mathrm{P}<0.05$ was considered to represent a statistically significant difference.

\section{Results}

Effects of soy isoflavones on body weight and colonic length in DSS-challenged mice. Body weight was recorded daily and is presented in Fig. 1A. On days 3 to 7, DSS treatment significantly reduced body weight in mice compared with the control group $(\mathrm{P}<0.05)$. Dietary soy isoflavones significantly increased body weight at day 5 in DSS-challenged mice compared with the DSS group $(\mathrm{P}<0.05)$. Average daily weight gain was significantly lower in the DSS compared with the control group (Fig. 1B; P<0.05), while dietary soy isoflavones failed to affect body weight gain in DSS-challenged mice (Fig. 1B; P>0.05).

Colonic length has been used as a clinical index for colonic inflammation and the present study demonstrated that DSS exposure significantly decreased colonic length $(\mathrm{P}<0.05$; Fig. 1C). Dietary soy isoflavones (SIF group) tended to alleviate DSS-induced colonic atrophy, however the difference was not significant.

Effects of soy isoflavones on inflammation in DSS-challenged mice. The mRNA abundances of interleukin (IL)-1 $\beta$, IL-6, IL-10, IL-17 and tumor necrosis factor (TNF)- $\alpha$ were measured via RT-qPCR to investigate the anti-inflammatory effect of soy isoflavones in DSS-challenged mice. The present data demonstrated that DSS treatment significantly induced colonic inflammation, indicated by the upregulation of IL-1 $\beta$, IL-6, IL-17 and TNF- $\alpha$ expression (Fig. 2A-D). IL-10 was also tested in this study; however, no significant difference was indicated ( $\mathrm{P}>0.05$; Fig. 2E). Dietary supplementation with isoflavones downregulated the expression of TNF- $\alpha$, compared with the DSS group $(\mathrm{P}<0.05$; Fig. 2D).

Effects of soy isoflavones on oxidative stress in DSS-challenged mice. MDA and T-AOC have been widely used as makers for oxidative stress and are indicated to be associated with inflammatory diseases. In the present study, DSS exposure significantly increased serum MDA concentration and decreased serum T-AOC activity compared with the control group $(\mathrm{P}<0.05$; Fig. $3 \mathrm{~A}$ and $\mathrm{B}$, respectively), suggesting that oxidative stress is associated with IBD. Although dietary soy isoflavones failed to significantly alleviate DSS-caused MDA generation, T-AOC activity in the SDS group was significantly higher than that in DSS group ( $\mathrm{P}<0.05$; Fig. 3B). Furthermore, RT-qPCR results (Fig. 3C-H) demonstrated that DSS significantly inhibited zinc-copper superoxide dismutase (ZnCuSOD; Fig. 3C) and glutathione peroxidase 1 (GPX1; Fig. 3D) gene expression levels (both $\mathrm{P}<0.05$ ), whereas dietary 
Table I. Polymerase chain reaction primer sequences: F and R primers used in the present study.

\begin{tabular}{|c|c|c|c|}
\hline Gene & Accession no. & Nucleotide sequence of primers, $5^{\prime}-3^{\prime}$ & Size, bp \\
\hline$\beta$-Actin & NM_007393.3 & $\begin{array}{l}\text { F: GTCCACCTTCCAGCAGATGT } \\
\text { R: GAAAGGGTGTAAAACGCAGC }\end{array}$ & 117 \\
\hline Occludin & NM_008756.2 & $\begin{array}{l}\text { F: ACTGGGTCAGGGAATATCCA } \\
\text { R: TCAGCAGCAGCCATGTACTC }\end{array}$ & 193 \\
\hline ZO1 & XM_006540786.1 & $\begin{array}{l}\text { F: ACTCCCACTTCCCCAAAAAC } \\
\text { R: CCACAGCTGAAGGACTCACA }\end{array}$ & 166 \\
\hline Caludin1 & NM_016674.4 & $\begin{array}{l}\text { F: AGACCTGGATTTGCATCTTGGTG } \\
\text { R: TGCAACATAGGCAGGACAAGAGTTA }\end{array}$ & 126 \\
\hline CAT & XM_006498624.1 & $\begin{array}{l}\text { F: AATATCGTGGGTGACCTCAA } \\
\text { R: CAGATGAAGCAGTGGAAGGA }\end{array}$ & 243 \\
\hline ZnCuSOD & NM_011434.1 & $\begin{array}{l}\text { F: CCACTGCAGGACCTCATTTT } \\
\text { R: CACCTTTGCCCAAGTCATCT }\end{array}$ & 216 \\
\hline Gpx1 & NM_008160.6 & $\begin{array}{l}\text { F: GGTTCGAGCCCAATTTTACA } \\
\text { R: CCCACCAGGAACTTCTCAAA }\end{array}$ & 199 \\
\hline Gpx2 & NM_030677.2 & $\begin{array}{l}\text { F: GTGTGATGTCAATGGGCAGAA } \\
\text { R: ACGTTTGATGTCAGGCTCGAT }\end{array}$ & 241 \\
\hline Gpx3 & NM_008161.3 & $\begin{array}{l}\text { F: GATGTGAACGGGGAGAAAGA } \\
\text { R: CCCACCAGGAACTTCTCAAA }\end{array}$ & 152 \\
\hline Gpx4 & NM_001037741.3 & $\begin{array}{l}\text { F: CTCCATGCACGAATTCTCAG } \\
\text { R: ACGTCAGTTTTGCCTCATTG }\end{array}$ & 117 \\
\hline IL-1 $\beta$ & NM_008361.3 & $\begin{array}{l}\text { F: CTGTGACTCGTGGGATGATG } \\
\text { R: GGGATTTTGTCGTTGCTTGT }\end{array}$ & 213 \\
\hline IL-6 & NM_031168.1 & $\begin{array}{l}\text { F: TGCAAGAGACTTCCATCCAGT } \\
\text { R: GTGAAGTAGGGAAGGCCG }\end{array}$ & 116 \\
\hline IL-10 & NM_010548.2 & $\begin{array}{l}\text { F: ACAGCCGGGAAGACAATAAC } \\
\text { R: CAGCTGGTCCTTTGTTTGAAAG }\end{array}$ & 116 \\
\hline IL-17 & NM_010552.3 & $\begin{array}{l}\text { F: TACCTCAACCGTTCCACGTC } \\
\text { R: TTTCCCTCCGCATTGACAC }\end{array}$ & 119 \\
\hline $\mathrm{TNF}-\alpha$ & NM_013693.2 & $\begin{array}{l}\text { F: AGGCACTCCCCCAAAAGAT } \\
\text { R: TGAGGGTCTGGGCCATAGAA }\end{array}$ & 192 \\
\hline TLR4 & NM_021297.3 & $\begin{array}{l}\text { F: TTTGCTGGGGCTCATTCACT } \\
\text { R: GACTCGGCACTTAGCACTGT }\end{array}$ & 164 \\
\hline Myd88 & NM_010851.2 & $\begin{array}{l}\text { F: CTCGCAGTTTGTTGGATGCC } \\
\text { R: GGCCACCTGTAAAGGCTTCT }\end{array}$ & 185 \\
\hline
\end{tabular}

F, forward; R, reverse; ZO1, zonula occludens-1; CAT, catalase; ZnCuSOD, zinc-copper superoxide dismutase; GPX, glutathione peroxidase; IL, interleukin; TNF- $\alpha$, tumor necrosis factor- $\alpha$; TLR4, toll-like receptor 4; Myd88, myeloid differentiation primary response gene 88.

soy isoflavones markedly upregulated ZnCuSOD, GPX1 and GPX4 mRNA expression levels $(\mathrm{P}<0.05$; Fig. 3C, D and G, respectively). However, gene expression levels of GPX2, GPX3 and CAT were not significant between groups ( $P>0.05$; Fig. 3E, F and H, respectively).

Effects of soy isoflavones on colonic morphology and tight junctions in DSS-challenged mice. No abnormal morphology was observed in the colon of mice in the control group (Fig. 4A). By contrast, villus height in the challenged mice exhibited a marked scattering and desquamation (Fig. 4B-D).
Villus height in the DSS group $(82.53 \pm 4.20 \mu \mathrm{m})$ was significantly lower than that in the control group $(103.25 \pm 3.77 \mu \mathrm{m}$; $\mathrm{P}<0.05)$ and soy isoflavones $(108.70 \pm 5.15 \mu \mathrm{m})$ significantly alleviated DSS-induced colonic villus injury $(\mathrm{P}<0.05$; Table II).

The present study further determined the expression of Occludin, zonula occludens-1 and Claudin1 (Fig. 4E-G) following DSS exposure, and the results demonstrated that DSS significantly downregulated the expression of Occludin and soy isoflavones enhanced the Occludin mRNA level $(\mathrm{P}<0.05$; Fig. 4E). 

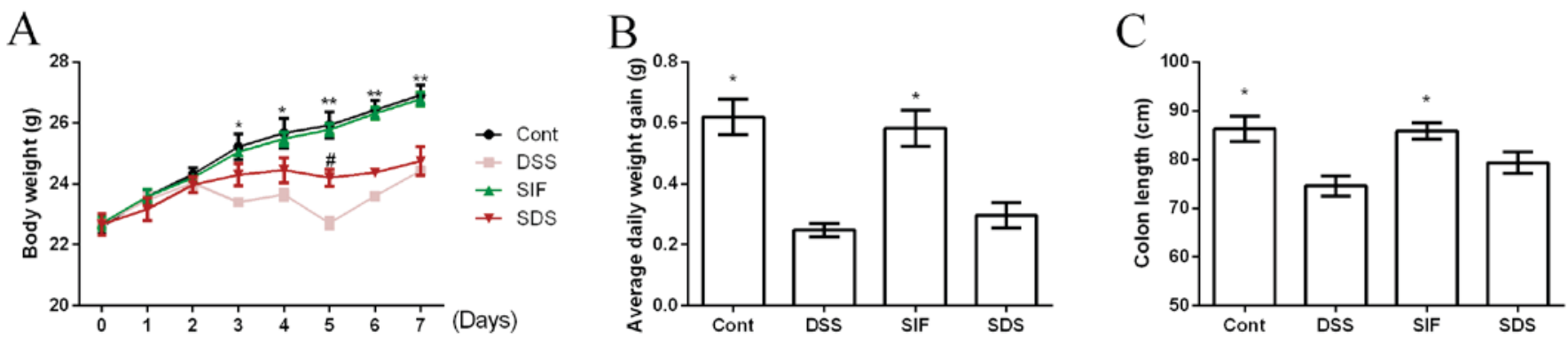

Figure 1. Effects of dietary soy isoflavones on (A) body weight, (B) average daily weight gain and (C) colon length. * $<<0.05$ and ${ }^{* *} \mathrm{P}<0.01$ vs. DSS group. ${ }^{\#} \mathrm{P}<0.05$ vs. DSS group. Data are presented as mean \pm standard error of the mean $(\mathrm{n}=6$ or 8$)$. DSS, dextran sulfate sodium treated group; SIF, soy isoflavones supplemented group; SDS, soy isoflavones and DSS-treated group; Cont, control group.

A
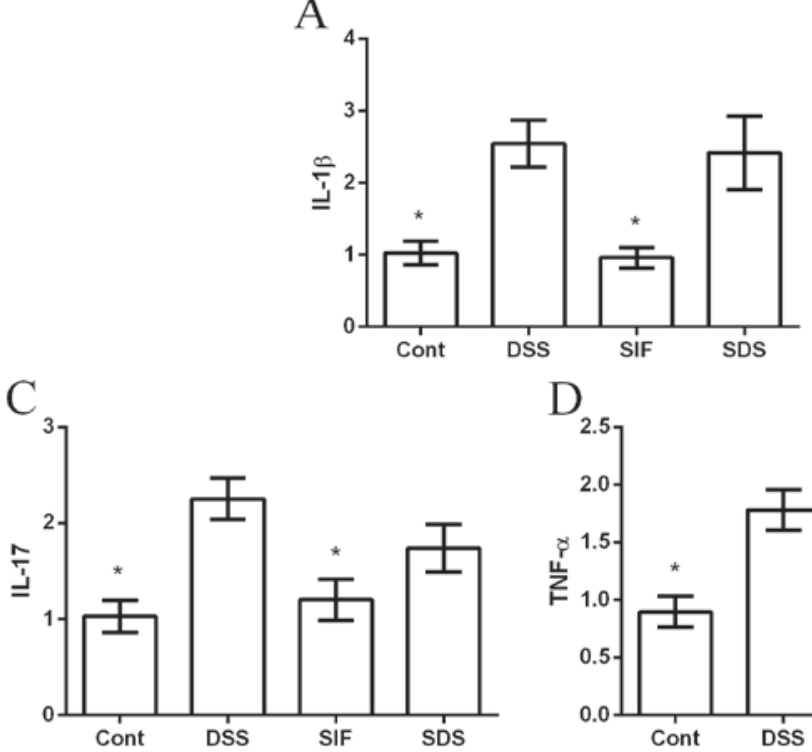

B

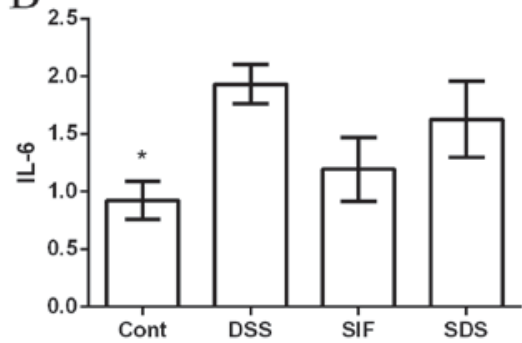

$\mathrm{E}$
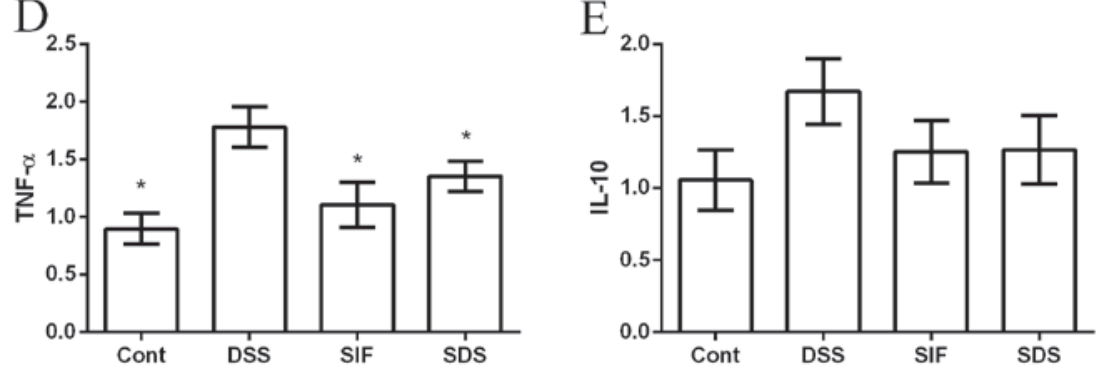

Figure 2. Effects of dietary soy isoflavones on the expression of colonic inflammatory cytokines (A) IL-1 $\beta$, (B) IL-6, (C) IL-17, (D) TNF- $\alpha$ and (E) IL-10. Data are presented as mean \pm standard error of the mean $(n=8)$. $\mathrm{P}<0.05$ vs. DSS group. Cont, control group; DSS, dextran sulfate sodium treated group; SIF, soy isoflavones supplemented group; SDS, soy isoflavones and DSS-treated group; IL, interleukin; TNF- $\alpha$, tumor necrosis factor- $\alpha$.

Effects of soy isoflavones on toll like receptor 4 (TLR4)/myeloid differentiation primary response gene 88 (Myd88) in DSS-challenged mice. TLR4/Myd88 is associated with various inflammatory responses (19). The present study demonstrated that DSS significantly enhanced the expression of colonic TLR4/Myd88 mRNA ( $\mathrm{P}<0.05$; Fig. 5), suggesting that DSS activates the TLR4/Myd88 signal. Although soy isoflavones tended to inhibit the TLR4 expression caused by DSS, the difference was not significant. However, dietary supplementation with soy isoflavones significantly inactivated Myd88 following DSS exposure ( $\mathrm{P}<0.05$; Fig. 5B).

\section{Discussion}

Soybeans, most widely used in Asian countries, are a rich source of biologically active isoflavones, such as genistein (4,5,7-trihydroxyisoflavone) and daidzein (4,7-dihydroxyisoflavone) known to have a spectrum of biological activities. Although soy isoflavones have been demonstrated to exert protective effects against a series of diseases in vitro and in vivo $(20,21)$, to the best of our knowledge no reports are available regarding the evaluation of soy isoflavones in inflammation and specifically in IBD. The present study demonstrated that dietary soy isoflavones reduced the severity and extent of progressive chronic colonic damage induced by a 7-day exposure of DSS.

Although the etiology of IBD remains essentially obscure, it has been suggested that the development and pathology may be associated with an abnormal inflammatory response in the gastrointestinal tract (22). Kim et al (22) reported that disease severity is often associated with an increase in higher levels of pro-inflammatory cytokines in experimental colitis. Pro-inflammatory cytokines are important mediators of inflammation and have distinguished roles in cancer development. The present study determined that there is an abundance of IL-1 $\beta$, IL-6, IL-10, IL-17 and TNF- $\alpha$ mRNA in the colon using RT-qPCR analysis and the results demonstrated that DSS-induced colonic inflammation. This was indicated by the upregulation of IL-1 $\beta$, IL-6, IL-17 and TNF- $\alpha$ gene expression. However, in DSS-challenged mice, dietary soy isoflavones downregulated the gene expression of TNF- $\alpha$. Similarly, soy isoflavones have also been demonstrated to alleviate inflammation induced by the generation of IL- $1 \beta$, IL-6 and TNF- $\alpha$ (23). IL-1 $\beta$, IL-6 and TNF- $\alpha$ have been implicated 

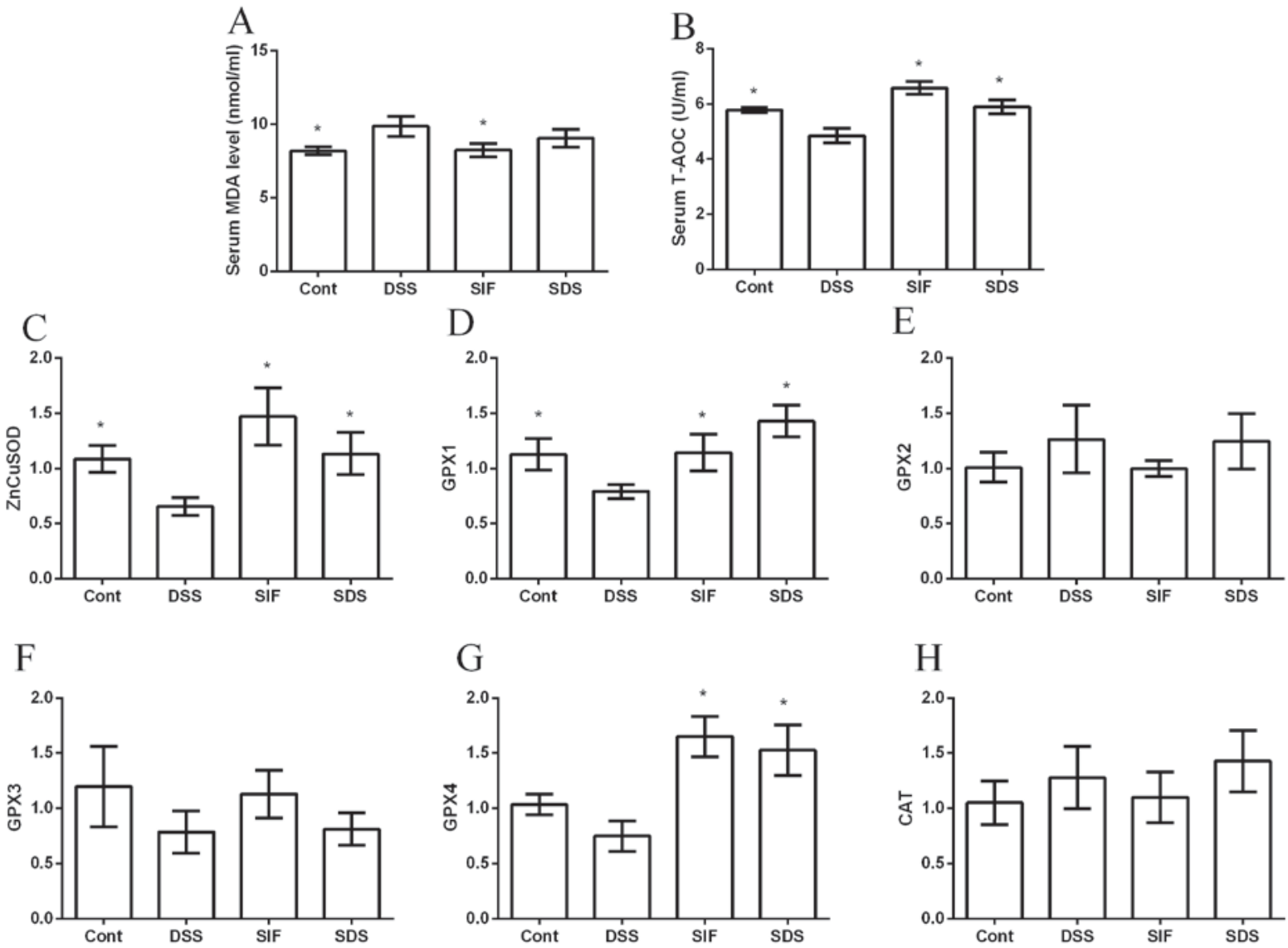

Figure 3. Effects of dietary soy isoflavones on oxidative stress following DSS exposure. The effects of dietary soy isoflavones on (A) MDA, (B) T-AOC, (C) ZnCuSOD, (D) GPX1, (E) GPX2, (F) GPX3, (G) GPX4 and (H) CAT. Data are presented as mean \pm standard error of the mean (n=6 or 8 ). "P<0.05 vs. DSS group. DSS, dextran sulfate sodium; MDA, Malondialdehyde; T-AOC, total antioxidant capability; ZnCuSOD, zinc-copper superoxide dismutase; GPX, glutathione peroxidase; CAT, catalase; Cont, control group; SIF, soy isoflavones supplemented group; SDS, soy isoflavones and DSS-treated group.

A

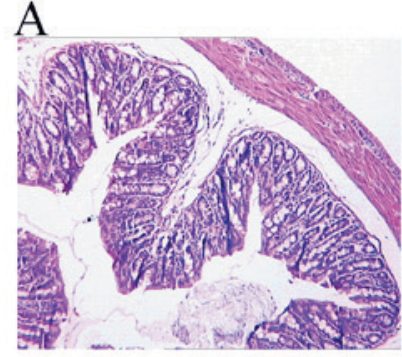

E

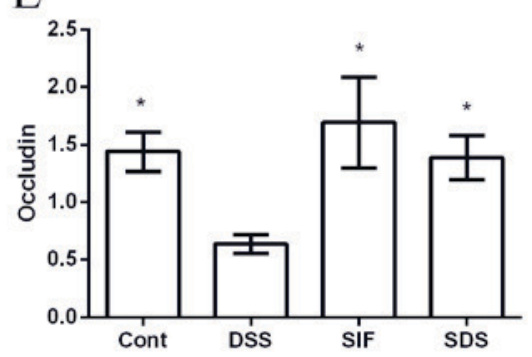

B

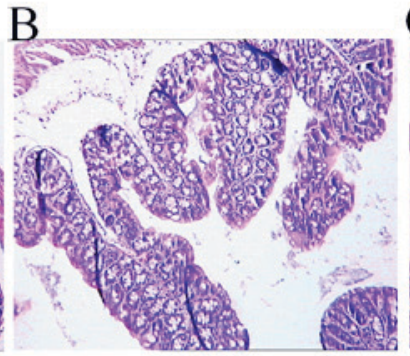

F

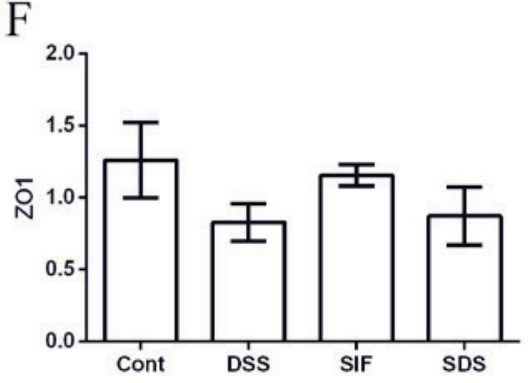

C
D

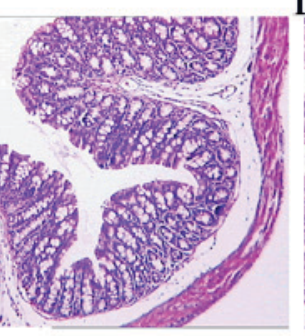

G

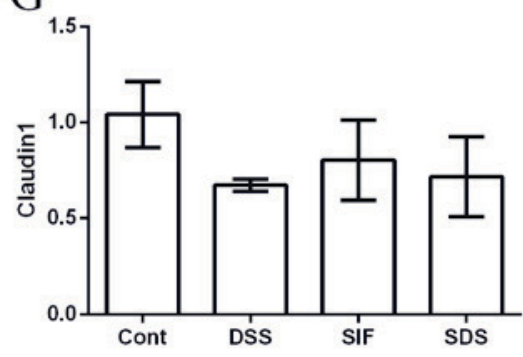

Figure 4. Effects of dietary soy isoflavones on histological structure and tight junction expression of Occludin, ZO1 and Claudin1. Hematoxylin and eosin staining of (A) control, (B) DSS, (C) SIF and (D) SDS groups at a magnification of x100. Quantified expression of (E) Occludin, (F) ZO1 and (G) Claudin1 following DSS exposure. Data are presented as mean \pm standard error of the mean $(n=8)$. ${ }^{*} \mathrm{P}<0.05$ vs. DSS group. DSS, dextran sulfate sodium treated group; SIF, soy isoflavones supplemented group; SDS, soy isoflavones and DSS-treated group; Cont, control group; ZO1, zonula occludens-1. 
Table II. Effects of dietary soy isoflavones on villus height $(\mu \mathrm{m})$ and crypt depth $(\mu \mathrm{m})$ in the colon following exposure to DSS.

\begin{tabular}{lrrrr}
\hline Item & Control & DSS & \multicolumn{1}{c}{ SIF } & SDS \\
\hline Villus height & $103.25 \pm 3.77^{\mathrm{a}}$ & $82.53 \pm 2.43$ & $108.70 \pm 5.15^{\mathrm{a}}$ & $100.05 \pm 3.56^{\mathrm{a}}$ \\
Crypt depth & $32.15 \pm 4.07$ & $31.57 \pm 1.68$ & $32.60 \pm 2.69$ & $34.60 \pm 3.01$ \\
V/C & $3.39 \pm 0.51$ & $2.64 \pm 0.20$ & $3.40 \pm 0.32$ & $2.96 \pm 0.26$ \\
\hline
\end{tabular}

Data are presented as mean \pm standard error of the mean $(n=4) .{ }^{a} \mathrm{P}<0.05$ vs. DSS. V/C, ratio of villus height to crypt depth; DSS, dextran sulfate sodium treated group; SIF, soy isoflavones supplemented group; SDS, soy isoflavones and DSS-treated group.

A

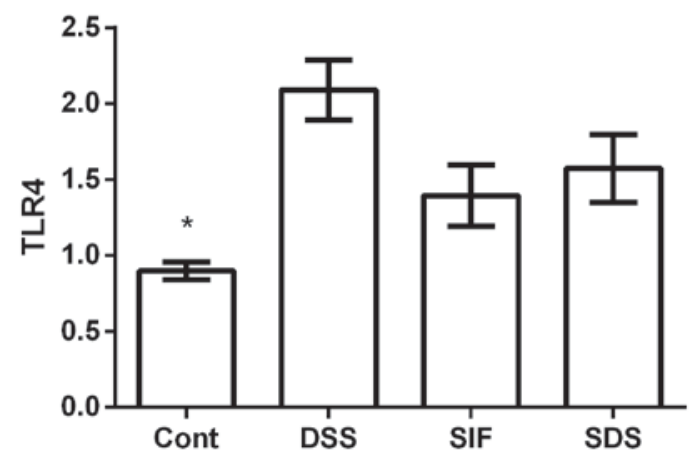

B

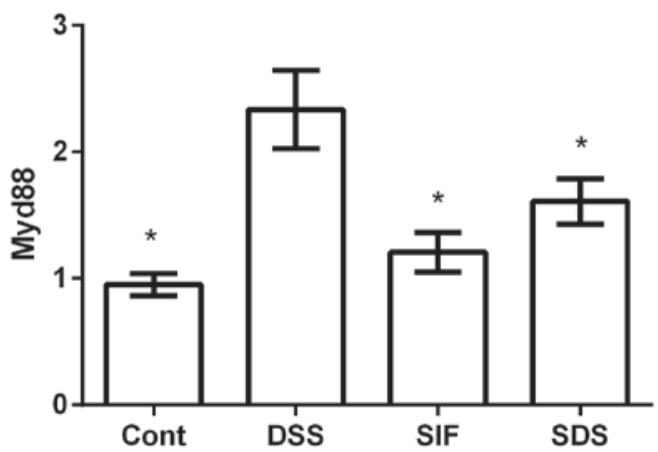

Figure 5. Effects of dietary soy isoflavones on (A) TLR4 and (B) Myd88 signal. Data are presented as mean \pm standard error of the mean (n=8). ${ }^{*}<0.05$ vs. DSS group. TLR4, toll-like receptor 4; Myd88, myeloid differentiation primary response gene 88; Cont, control group; DSS, dextran sulfate sodium treated group; SIF, soy isoflavones supplemented group; SDS, soy isoflavones and DSS-treated group.

in a number of cellular and molecular mechanisms associated with the majority of inflammation-associated chronic human diseases, including IBD (23). Thus, the present study speculated that soy isoflavones have evident anti-inflammatory potential in the IBD model.

Studies on the antioxidant function of soy isoflavones have suggested a free radical scavenging ability, an ability to reduce low-density lipoprotein and DNA susceptibility to oxidative stress, and an ability to boost the activity and expression of antioxidant enzymes (14). Due in part to their potential antioxidant activities; soy isoflavones have been linked to a decreased risk of cardiovascular disease, osteoporosis, endocrine-responsive cancer and inflammatory diseases $(24,25)$. MDA and T-AOC have been widely used as makers for oxidative stress $(26,27)$. In the present study, DSS exposure significantly induced oxidative stress, indicated by the elevated MDA level and decreased T-AOC activity. Although dietary soy isoflavones failed to alleviate DSS-induced MDA generation, soy isoflavones enhanced serum T-AOC activity, suggesting an antioxidant function of soy isoflavones in the DSS-induced IBD model. To investigate the antioxidant mechanism of soy isoflavones, the present study further determined colonic antioxidant gene expression. The results demonstrated that dietary soy isoflavones upregulated the gene expression levels of $\mathrm{ZnCuSOD,} \mathrm{GPX1}$ and GPX4 in DSS-challenged mice. In the exercise-induced oxidative stress model, Yoon and Park (14) reported that soy isoflavones significantly enhanced SOD activity and alleviated oxidative injury. GPX1 and GPX4 have been revealed to be involved in IBD via regulating $\mathrm{T}$ cell function and oxidative stress $(28,29)$. Thus, the antioxidant function of soy isoflavones in IBD model may be associated with increasing the expression of ZnCuSOD, GPX1 and GPX4.

Dysfunction of the gastrointestinal barriers is a major characteristic symptom in the pathophysiology of IBD (30). In the present study, dietary soy isoflavones significantly alleviated DSS-induced colonic villus injury and upregulated occludin expression in DSS-challenged mice. This indicated a beneficial role in intestinal morphologic structure and barrier function. Kiatprasert et al (31) reported that treatment with soy isoflavones may promote and restore the impaired endometrial barrier function by increasing the gene expression of tight junction-associated genes in lipopolysaccharide-induced inflammation.

TLR4/Myd88 signalling is associated with various inflammatory diseases, including IBD $(32,33)$. Cao et al $(33)$ demonstrated that TLR4/Myd88 is able to regulate interferon- $\gamma$ and IL-17 production by inducing Foxp $3^{+}$regulatory $\mathrm{T}$ cells during intestinal inflammation. It has also been suggested that TLR4/Myd88 is able to mediate the NF- $\kappa \mathrm{B}$ pathway and maintain the intestinal barrier function (34). In the present study, DSS activated TLR4/Myd88 and dietary soy isoflavones significantly inhibited Myd88 expression. Genistein, a principal soy isoflavone, has been revealed to mediate TLR4/Myd88 in various inflammations $(35,36)$. In addition, genistein attenuated the initiation of intracellular signaling cascades by LPS through inhibiting NF- $\kappa \mathrm{B}$ activation by inhibiting the binding of LPS to TLR-4 on microglial cells (37).

In conclusion, DSS caused inflammation, oxidative stress, intestinal barrier dysfunction in mice. However, findings from the present study demonstrated that dietary soy isoflavones 
alleviated DSS-induced inflammation in mice, which may be associated with enhancing antioxidant function and inhibiting the TLR4/MyD88 signal.

\section{Acknowledgements}

The present study was supported by Scientific Research Program of Jiangsu Provincial Huaian Municipal Government (grant no. HAN2014007).

\section{References}

1. Dubeau MF, Iacucci M, Beck PL, Moran GW, Kaplan GG Ghosh S and Panaccione R: Drug-induced inflammatory bowel disease and IBD-like conditions. Inflamm Bowel Dis 19: 445-456, 2013

2. Ananthakrishnan AN: Epidemiology and risk factors for IBD. Nat Rev Gastroenterol Hepatol 12: 205-217, 2015.

3. Mileva S, Galunska B, Gospodinova M, Gerova D and Svinarov D: Vitamin D3 status in children with acute diarrhea. Integr Food Nutr Metab 1: 1-6, 2014.

4. Hirai $\mathrm{F}$ and Matsui T: Status of food intake and elemental nutrition in patients with Crohn's disease. Integr Food Nutr Metab 2: 148-150. 2015.

5. Naito Y, Takagi T and Yoshikawa T: Neutrophil-dependent oxidative stress in ulcerative colitis. J Clin Biochem Nutr 41: 18-26. 2007.

6. Sann H, Erichsen Jv, Hessmann M, Pahl A and Hoffmeyer A: Efficacy of drugs used in the treatment of IBD and combinations thereof in acute DSS-induced colitis in mice. Life Sci 92: 708-718. 2013.

7. Piechota-Polanczyk A and Fichna J: Review article: The role of oxidative stress in pathogenesis and treatment of inflammatory bowel diseases. Naunyn Schmiedebergs Arch Pharmacol 387 605-620. 2014

8. Zhu H and Li YR: Oxidative stress and redox signaling mechanisms of inflammatory bowel disease: Updated experimental and clinical evidence. Exp Biol Med (Maywood) 237: 474-480. 2012.

9. Almenier HA, Al Menshawy HH, Maher MM and Al Gamal S: Oxidative stress and inflammatory bowel disease. Front Biosci (Elite Ed) 4: 1335-1344, 2012.

10. Shori AB and Baba AS: Fermented milk derives bioactive peptides with antihypertensive effects. Integr Food Nutr Metab 2: 178-181, 2015.

11. McCann MJ, Dalziel JE, Bibiloni R and Barnett MPG: An integrated approach to assessing the bio-activity of nutrients in vitro: The anti-oxidant effects of catechin and chlorogenic acid as an example. Integr Food Nutr Metab 2: 197-204, 2015.

12. Mahmoud AM, Yang W and Bosland MC: Soy isoflavones and prostate cancer: A review of molecular mechanisms. J Steroid Biochem Mol Biol 140: 116-132, 2014

13. Yin J, Wu M, Duan J, Liu G, Cui Z, Zheng J, Chen S, Ren W, Deng J, Tan X, et al: Pyrrolidine dithiocarbamate inhibits NF-KappaB activation and upregulates the expression of Gpx1, Gpx4, occludin, and ZO-1 in DSS-induced colitis. Appl Biochem Biotechnol 177: 1716-1728, 2015.

14. Yoon GA and Park S: Antioxidant action of soy isoflavones on oxidative stress and antioxidant enzyme activities in exercised rats. Nutr Res Pract 8: 618-624, 2014.

15. Yin J, Liu M, Ren W, Duan J, Yang G, Zhao Y, Fang R, Chen L, Li T and Yin Y: Effects of dietary supplementation with glutamate and aspartate on diquat-induced oxidative stress in piglets. PLoS One 10: e0122893, 2015.

16. Yin J, Duan J, Cui Z, Ren W, Li T and Yin Y: Hydrogen peroxide-induced oxidative stress activates $\mathrm{NF}-\kappa \mathrm{B}$ and Nrf2/Keap1 signals and triggers autophagy in piglets. RSC Advances 5: 15479-15486, 2015.

17. Yin J, Wu MM, Xiao H, Ren WK, Duan JL, Yang G, Li TJ and Yin YL: Development of an antioxidant system after early weaning in piglets. J Anim Sci 92: 612-619, 2014.
18. Livak KJ and Schmittgen TD: Analysis of relative gene expression data using real-time quantitative PCR and the 2(-Delta Delta C(T)) Method. Methods 25: 402-408, 2001.

19. Doz E, Noulin N, Boichot E, Guénon I, Fick L, Le Bert M, Lagente V, Ryffel B, Schnyder B, Quesniaux VF and Couillin I: Cigarette smoke-induced pulmonary inflammation is TLR4/MyD88 and IL-1R1/MyD88 signaling dependent. J Immunol 180: 1169-1178, 2008.

20. Pudenz M, Roth K and Gerhauser C: Impact of soy isoflavones on the epigenome in cancer prevention. Nutrients 6: 4218-4272, 2014.

21. Hillman G G and Singh-Gupta V: Soy isoflavones sensitize cancer cells to radiotherapy. Free Radic Biol Med 51: 289-298, 2011.

22. Kim JJ, Shajib MS, Manocha MM and Khan WI: Investigating intestinal inflammation in DSS-induced model of IBD. J Vis Exp pii: 3678, 2012.

23. Khan AQ, Khan R, Rehman MU, Lateef A, Tahir M, Ali F and Sultana S: Soy isoflavones (daidzein \& genistein) inhibit 12-O-tetradecanoylphorbol-13-acetate (TPA)-induced cutaneous inflammation via modulation of COX-2 and NF- $\mathrm{BB}$ in Swiss albino mice. Toxicology 302: 266-274, 2012.

24. Arteel GE, Uesugi T, Bevan LN, Gäbele E, Wheeler MD, McKim SE and Thurman RG: Green tea extract protects against early alcohol-induced liver injury in rats. Biol Chem 383: 663-670, 2002.

25. Yousef MI, Kamel KI,Esmail AM and Baghdadi HH: Antioxidant activities and lipid lowering effects of isoflavone in male rabbits. Food Chem Toxicol 42: 1497-1503, 2004.

26. Yin J, Ren W, Yang G, Duan J, Huang X, Fang R, Li C, Li T, Yin Y, Hou Y, et al: 1-Cysteine metabolism and its nutritional implications. Mol Nutr Food Res 60: 134-146. 2016.

27. Yin J, Ren W, Liu G, Duan J, Yang G, Wu L, Li T and Yin Y: Birth oxidative stress and the development of an antioxidant system in newborn piglets. Free Radic Res 47: 1027-1035, 2013.

28. Häuser F, Rossmann H, Laubert-Reh D, Wild PS, Zeller T, Müller C, Neuwirth S, Blankenberg S and Lackner KJ: Inflammatory bowel disease (IBD) locus 12: Is glutathione peroxidase-1 (GPX1) the relevant gene? Genes Immun 16: 571-575, 2015.

29. Kim HR, Lee A, Choi EJ, Kie JH, Lim W, Lee HK, Moon BI and Seoh JY: Attenuation of experimental colitis in glutathione peroxidase 1 and catalase double knockout mice through enhancing regulatory T cell function. PLoS One 9: e95332, 2014

30. Amasheh M, Grotjohann I, Amasheh S, Fromm A, Söderholm JD, Zeitz M, Fromm M and Schulzke JD: Regulation of mucosal structure and barrier function in rat colon exposed to tumor necrosis factor alpha and interferon gamma in vitro: A novel model for studying the pathomechanisms of inflammatory bowel disease cytokines. Scand J Gastroenterol 44: 1226-1235, 2009.

31. Kiatprasert P, Deachapunya C, Benjanirat $C$ and Poonyachoti S: Soy isoflavones improves endometrial barrier through tight junction gene expression. Reproduction 149: 269-280, 2015.

32. Ma W, Wang J, Li Y, Hu X, Shi F and Wang X: Enhancing pentose phosphate pathway in Corynebacterium glutamicum to improve l-isoleucine production. Biotechnol Appl Biochem 63: 877-885, 2016

33. Cao AT, Yao S, Stefka AT, Liu Z, Qin H, Liu H, Evans-Marin HL, Elson CO, Nagler CR and Cong Y: TLR4 regulates IFN- $\gamma$ and IL-17 production by both thymic and induced Foxp3 ${ }^{+}$Tregs during intestinal inflammation. J Leukoc Biol 96: 895-905, 2014.

34. Wang W, Xia T and Yu X: Wogonin suppresses inflammatory response and maintains intestinal barrier function via TLR4-MyD88-TAK1-mediated NF- $\kappa$ B pathway in vitro. Inflamm Res 64: 423-431, 2015.

35. Dijsselbloem N, Goriely S, Albarani V, Gerlo S, Francoz S, Marine JC, Goldman M, Haegeman G and Vanden Berghe W: A critical role for p53 in the control of NF-kappaB-dependent gene expression in TLR4-stimulated dendritic cells exposed to Genistein. J Immunol 178: 5048-5057, 2007.

36. Yu HL, Li XY, Zhou X, Yuan LH, Ma WW, Xi YD, Zhao X, Wu J and Xiao R: Beta amyloid peptide (25-35) leading to inflammation through Toll-like receptors and the anti-inflammatory effect of genistein in BV-2 cells. J Mol Neurosci 51: 771-778, 2013.

37. Jeong JW, Lee HH, Han MH, Kim GY, Kim WJ and Choi YH: Anti-inflammatory effects of genistein via suppression of the toll-like receptor 4-mediated signaling pathway in lipopolysaccharide-stimulated BV2 microglia. Chem Biol Interact 212: 30-39, 2014. 